\title{
Lack of Correlation between Periodontitis and Renal Dysfunction in Systemically Healthy Patients
}

\author{
Renata Squariz Brotto ${ }^{a}$ \\ Regina Célia Vendramini \\ Iguatemy Lourenço Brunettia \\ Rosemary Adriana Chierici Marcantonio ${ }^{b}$ \\ Adriana Pelegrino Pinho Ramos ${ }^{c}$ \\ Maria Teresa Pepato
}

\section{ABSTRACT}

Objectives: The aim of this study was to assess a suggested association between periodontitis and renal insufficiency by assaying kidney disease markers.

Methods: Variables used to diagnose periodontitis were: (i) probing pocket depth (PPD), (ii) attachment loss (AL), (iii) bleeding on probing (BOP), (iv) plaque index (PI) and (v) extent and severity index. Blood and urine were collected from 60 apparently healthy non-smokers (men and women), consisting of a test group of 30 subjects with periodontitis lage $46 \pm 6 \mathrm{yrs}$ ) and a control group of 30 healthy subjects (age $43 \pm 5 \mathrm{yrs}$ ). Kidney function markers (urea, creatinine, uric acid and albumin contents) were measured in the serum and urine. Also, the glomerular filtration rate was estimated from creatinine clearance, from the abbreviated Modification of Diet in Renal Disease formula and from the albumin : creatinine ratio in a $24-\mathrm{h}$ sample of urine.

Results: It was found that the control group had a greater mean number of teeth than the test group and that the two groups also differed in PPD, AL, BOP and PI, all these variables being higher in the test group $(P=0.006)$. For the extent and severity index of both PPD and $A L$, the test group had much higher medians of both extent and severity than the control group $(P=0.001)$. With regard to kidney function, none of the markers revealed a significant difference between the control and test groups and all measured values fell within the reference intervals.

Conclusions: It is proposed that severe periodontitis is not associated with any alteration in kidney function. (Eur J Dent 2011;5:8-18)

Key words: Kidney function markers; Creatinine clearance; Albumin; Urea; Uric acid.

a Faculdade de Ciências Farmacêuticas de Araraquara - UNESP - Univ Estadual Paulista Departamento de Análises Clínicas, SP, Brasil.

b Faculdade de Odontologia de Araraquara UNESP- Univ Estadual Paulista - Departamento de Diagnóstico e Cirurgia, SP, Brasil.

Laboratório de Análises Clínicas do Curso de Ciências Farmacêuticas - Universidade de Ribeirão Preto (UNAERP), São Paulo, Brasil.
Corresponding author: Profa. Dra. Maria Teresa Pepato Departamento de Análises Clínicas Faculdade de Ciências Farmacêuticas de Araraquara Universidade Estadual Paulista Júlio de Mesquita Filho - UNESP Rua Expedicionários do Brasil $n$.

1621 Araraquara - SP, Brazil 14801- 902 Phone: 551633016546 Fax: 551633320486 E-mail: pepatomtafcfar.unesp.br 


\section{INTRODUCTION}

Chronic periodontitis, the commonest type of periodontal disease, is defined by the American Academy of Periodontology as an infectious disease resulting in inflammation within of the tissues supporting the teeth, progressive loss of attachment and bone loss. This process leads to pocket formation around the tooth and/or gum recession. ${ }^{1}$ This definition is based on a model of infection and host response which, despite the extent of current knowledge on periodontal diseases, is still inadequate for a diagnosis leading to a full classification grounded in the etiology of the disease. ${ }^{2}$

In chronic periodontitis, the bacterial biofilm is assumed to be the etiological agent, implying that this disease is polymicrobial. In the community of bacteria beneath the gums, the gram-negative bacteria are recognized as periodontal pathogens ${ }^{3}$ and studies that take into account variables linked to the genetics of both patients and these potential pathogens are likely to give a better insight into the etiology of periodontal disease. ${ }^{4}$

There have been signs that periodontitis may contribute to chronic systemic disease. Thus, some results have revealed an association between periodontitis and atherosclerotic vascular disease. ${ }^{5-8}$ The explanation offered for this connection is that periodontal pathogens could circulate in the bloodstream and promote damage to blood vessel endothelium and atherosclerosis.

It is plausible that such damage occurs not only in the endothelia of the heart and brain but also in kidney endothelium. Certainly, it is known that various chronic and acute infections are able to incite an inflammatory response in the kidney called glomerulonephritis. ${ }^{9}$ This is a relevant and timely topic because the prevalence of kidney disease is increasing and the majority of patients suffering from kidney disease also suffer from periodontitis. ${ }^{10}$ One United States population-based study considers multiple risk factors, including periodontal status, in the identification of individuals at high risk of chronic kidney disease. ${ }^{11}$

With this in mind, some researchers have turned their attention to the relation between periodontitis and renal insufficiency and the results of some work carried out on dogs ${ }^{12}$ and on humans ${ }^{9}$ confirmed this relation. On the other hand, Yamalik et $\mathrm{al}^{13}$ observed that bacterial accumulation was similar in systemically healthy individuals with periodontitis and patients with chronic renal failure and periodontitis. Also, no significant differences were observed in mean gingival-periodontal index, probing pocket depth or bleeding index between individuals with and without chronic renal failure. ${ }^{14}$ Fisher et $\mathrm{al}^{15}$ showed that edentulism and periodontitis were independently associated with chronic kidney disease.

Thus, in light of the above controversy and given that the nature of this association is not fully understood, we believe that further investigation is necessary.

One little-used approach to studying this association is to test the hypothesis that periodontitis is correlated with the start of the development of kidney disease. To this end, this study was designed to assess i) the correlation between periodontitis and the levels of kidney function markers in systemically healthy subjects and ii) the distribution of these levels relative to their reference intervals. The classic markers for kidney function $^{16-19}$ used in this study were the levels of albumin and non-protein nitrogen compounds in the serum and urine, albumin/urinary creatinine ratio, creatinine clearance, the abbreviated Modification of Diet in Renal Disease formula for predictive estimation of glomerular filtration rates and urinary volume.

\section{MATERIALS AND METHODS}

Patient selection

This cross-sectional study (case-control) was conducted from November 2005 to July 2007, after the protocol had been approved (Res.196/05) by the human subject ethics committee of the UNESP School of Dentistry at Araraquara, SP, Brazil, and written informed consent was obtained prior to subject enrollment. The sample size was calculated for $\alpha=5 \%$, with $1.0 \mathrm{~mm}$ significant difference in clinical measurements between groups, and a standard deviation of $0.8 \mathrm{~mm}$. Therefore, with a sample size of 27 patients, the power of the significance test was calculated to be $85 \%$. A total of 60 subjects were thus included in the study and divided into two groups of 30 participants each. All subjects in both groups were between 32 and 58 years old.

Thirty-six chronic periodontitis subjects $(\geq 14$ teeth in the mouth (including third molars), of 
which 4 had at least one site with probing pocket depth (PPD) of 3 to $5 \mathrm{~mm}$, and 4 others at least one site with 6 to $10 \mathrm{~mm} \mathrm{PPD}^{1}$ ] were recruited from the Periodontal Clinic of the São Paulo State University (UNESP) School of Dentistry at Araraquara, SP, Brazil to form the test group. Six subjects had to be excluded from the group because they did not appear for the collection of biological material, hence, a final of thirty subjects were formed the group. Thirty periodontally healthy volunteers ( $\geq 14$ teeth in the mouth including third molars, bleeding on probing (BOP) at $<30 \%$ of periodontal sites with PPD of 1 to $3 \mathrm{~mm}$, only 2 isolated sites with PPD of $4 \mathrm{~mm}$ and without BOP, and attachment loss (AL) of $3 \mathrm{~mm}$ or more at $<30 \%$ of all the sites in the mouth ${ }^{1,20,21}$ from Araraquara city (blood donors and others) not barred by the exclusion criteria were identified and recruited to the control group. Exclusion criteria for both groups were; unfavorable systemic conditions (rheumatic fever or heart problems requiring prophylactic antibiotic treatment and kidney disease), pregnant women, women on hormone replacement therapy or hormonal contraceptives, patients taking steroidal or non-steroidal anti-inflammatory drugs (previous 3 months) or antibiotics (previous 6 months), smokers and subjects showing high-sensitivity $\mathrm{C}$-reactive protein (CRP) above 10 $\mathrm{mg} / \mathrm{L}$, these being powerful conditions that could have affected the progression of periodontitis. ${ }^{22,23}$

Both the control and test groups were instructed on how to perform appropriate oral hygiene and were given preventive or curative oral treatment.

The full-mouth periodontal examination Isix sites per tooth: mesio-buccal, mid-buccal, distobuccal, mesio-lingual, mid-lingual, disto-lingual) was performed by one calibrated examiner using Williams probe (Hu-Friedy Manufacturing Co., Chicago, USAl of circular cross-section. The following parameters were assessed at the 6 sites around each tooth: (i) PPD, (ii) AL, (iii) BOP and (iv) plaque index (PI). AL was determined from the distance between the cementoenamel junction and the most apical part of the periodontal pocket. BOP indicates the presence (+) or absence (-) of bleeding after probing the pocket. The presence $(+)$ or absence (-) of plaque was observed on the mesial, buccal, distal and lingual faces of each tooth and the PI was calculated. The extent and severity index for periodontitis was calculated from clinical variables (PPD and $A L$ ) used to diagnose periodontitis; measurements indicating periodontitis were considered to be $\mathrm{AL}>2 \mathrm{~mm}$ and $\mathrm{PPD}$ $>2 \mathrm{~mm}$. The extent of the disease was taken as the proportion of all sites examined that showed pathological symptoms, both for AL and PPD. Severity was calculated from the scores assigned to $\mathrm{AL}$ and PPD at each site: for each $\mathrm{mm}$ beyond 2 $\mathrm{mm}$ (normal), the score was incremented by 1 and the sum of scores was divided by the number of abnormal sites. ${ }^{20,21,24}$

\section{Laboratory tests}

Venous blood samples were taken $18 \mathrm{~mL}$ in evacuated tubel from subjects after fasting for 12 h overnight. The 24-hour period of urine collection ended on the morning of the blood collection. The serum and urinary levels of renal function markers (urea, creatinine, uric acid and albumin) were measured $^{16}$ and the glomerular filtration rate was estimated from creatinine clearance, ${ }^{17}$ from the abbreviated Modification of Diet in Renal Disease formula ${ }^{18}$ and from the albumin $(\mathrm{mg}) /$ creatinine (g) ratio in the 24 -hour urine sample. ${ }^{19}$ Serum and urinary urea were determined by enzyme assay $^{25}$ in which urea was hydrolyzed by urease to ammonia, which was assayed by measuring the UV absorbance of NADH consumed in the presence of glutamate dehydrogenase. Creatinine was analyzed by the Lustosa-Basques colorimetric method ${ }^{25}$ based on the absorbance of colored complexes formed by picrate with creatinine and with interfering compounds, at alkaline $\mathrm{pH}$; when acetic acid is added, the creatinine-picrate complex is destroyed and the difference between the two absorbances is proportional to the amount of creatinine. The uricase assay ${ }^{25}$ was used to measure uric acid; the latter is first oxidized while oxygen is converted to hydrogen peroxide, which is then assayed by reaction with peroxidase and a chromogen. Serum albumin was determined by reaction with bromocresol green, ${ }^{26}$ which forms a complex with albumin that absorbs at a specific wavelength in the visible. Albuminuria was assessed quantitatively by an immunonephelometric method ( $N$ antiserum to human albumin), following the nephelometer kit manufacturer's instructions (Dade-Behring $\mathrm{GmbH}$, Marburg, Germany). Serum and urinary determinations of urea, uric acid, creatinine and albumin were performed in a 
Technicon RA-XT autoanalyser (Dublin, Ireland). The reagents for quantitation of serum and urinary uric acid were from Kovalent do Brasil Ltda. (São Gonçalo, Rio de Janeiro), while those for serum albumin and serum and urinary urea and creatinine were from the Labtest Diagnostics S.A. kit (Belo Horizonte, Brazil). Serum and urine samples were analyzed immediately after collection from the subjects.

\section{Statistical analysis}

The Chi-square test was used to determine whether a group lay outside or within the reference interval for a given variable, according to the frequency of subjects in each category.

To compare means of quantitative variables in groups, Student's t-test was used, in conjunction with either a post-hoc Mann-Whitney non-parametric test or a prior log transformation of the data prior to testing. In all statistical tests, significance was accepted when $\mathrm{P}<.05$.

The data for the controls and those for the test group were also separately subjected to multivariate canonical correlation analysis, employing SAS software, in order to reveal correlations between their canonical variables for the periodontal diagnosis variables (number of teeth and values of PPD, AL, BOP and PI) and the kidney function markers (serum albumin and uric acid, serum and urinary creatinine and urea, urinary volume, creatinine clearance, abbreviated Modification of Diet in Renal Disease formula and albumin/creatinine ratio).

\section{RESULTS}

The distribution of sexes in the control and test groups was similar: 13 men and 17 women controls and 16 men and 14 women in the test group. There was also no significant difference in age, as the means and standard deviations were $43 \pm 5 \mathrm{yrs}$ and $46 \pm 6$ yrs for the respective groups.

In Table 1, it can be seen that the two groups had different mean numbers of teeth and also differed with respect to PPD, AL, BOP and PI. The PPD and AL results were classified as follows: $<3 \mathrm{~mm}$ (shallow), 3-5 mm (medium) and $\geq 6 \mathrm{~mm}$ (deep), and the pattern of these classes differed appreciably between the groups; thus, only the test group showed deep pockets. The number of teeth and proportion of shallow pockets (PPD and ALI among the sites were higher in the control group, while higher values of all other variables were found in the test group $(P=0.006)$. For the extent and severity index of both PPD and AL, the test group had a centre of distribution (median) much higher than that of the control group $(P=0.001)$. The serum and urinary levels of the kidney function indicators in both groups are presented in Table 2. No significant differences were revealed between the two groups in the mean values of any of these variables. The same was true of the glomerular filtration rate-related variables: creatinine clearance (mean), abbreviated Modification of Diet in Renal Disease formula (median) and the urinary albumin/creatinine ratio (median) (Table 3). The absolute and percent frequencies of the renal function indicators found inside and outside their reference intervals in the two groups are displayed in Table 4. Whichever variable is analyzed, it can be seen that there is no evidence that the frequency of results within or outside the reference interval is different in the control and test groups. The same was found for the glomerular filtration rate variables (Table 5). Multivariate canonical correlation analysis, applied to the control group, revealed that larger numbers of teeth and of sites with $\mathrm{PPD}<3 \mathrm{~mm}$ and $\mathrm{AL}<3 \mathrm{~mm}$, and low $\mathrm{BOP}$ and $\mathrm{PI}$, are associated with higher levels of serum uric acid, urinary urea and urinary volume, though these levels remained within the respective reference intervals. In addition, a large number of sites with PPD between 3 and $5 \mathrm{~mm}$ correlated with higher rates of creatinine clearance. Analyzing the test group, it was found that larger numbers of sites with PPD $<3 \mathrm{~mm}$ and low BOP were both associated with higher levels of urinary creatinine and creatinine clearance and lower levels of serum albumin. Also in the test group, it was observed that small numbers of sites with PPD > $6 \mathrm{~mm}$ correlated with lower albumin/ creatinine ratios and large numbers of teeth with high serum urea levels. Finally, in the test group, low PI was associated with higher levels of serum and urinary uric acid.

\section{DISCUSSION}

In this study, we investigated the possible association between periodontitis and renal insufficiency by assaying kidney disease markers in two groups of subjects, previously diagnosed 
with periodontitis (test group) and periodontally healthy (control group).

In the control group shallow pockets were found at $90 \%$ of all sites, according to the $A L$ and PPD data. The control group showed $\mathrm{AL}$ at around $7.63 \%$ of sites and a median severity of $1.0 \mathrm{~mm}$, while in the test group, AL was recorded at $62.44 \%$ of sites, with a median severity of $2.58 \mathrm{~mm}$. Thus, an 8 times greater proportion of sites within the mouth was affected by loss of attachment in the test group and it was $158 \%$ more severe in the test group than in the control group. Analyzing the results for PPD, the control group had low values while the test group values were higher. With respect to extent, more than $50 \%$ of the sites were affected in the test group, while the severity had a median value of $2.25 \mathrm{~mm}$, against $5.23 \%$ and $1.00 \mathrm{~mm}$ for the control group. Therefore, the two groups were certainly quite distinct, proving that the test group members had severe periodontitis, while the controls did not.

The results demonstrated that patients with periodontitis suffered no alteration in the level of any of the blood or urinary indicators of renal dysfunction, relative to the control group, and furthermore these markers stayed within their normal ranges in both groups, suggesting that severe periodontitis does not affect renal function. These findings were obtained from 8 direct and 3 indirect markers of renal function. Moreover, microalbuminuria, which was similar in the control and test groups, was also within its reference interval in both groups. ${ }^{32}$

Several studies have been published showing correlation between periodontitis and renal dysfunction, some of which involve specific bacterial species. According to Socransky et al, ${ }^{33}$ the microorganisms responsible for periodontitis belong to the red complex (Porphyromonas gingivalis, Tanerella forsythia and Treponema dentícola), while Send et $\mathrm{al}^{{ }^{34}}$ report that there is considerable evidence that periodontitis-related microorganisms impair blood rheological parameters and thereby contribute significantly to accelerated systemic or local diseases that cause premature death in dialyzed patients.

In the majority of published work on this association, the case group consists of patients with

Table 1. Oral variables assessed in the periodontal diagnosis.

\begin{tabular}{|c|c|c|c|c|c|}
\hline \multirow[b]{2}{*}{ Variable } & \multicolumn{2}{|c|}{ Control group } & \multicolumn{2}{|c|}{ Test group } & \\
\hline & Mean \pm SD & Median (range) & Mean \pm SD & Median (range) & \\
\hline Number of teeth & $28.0 \pm 3.0$ & $28.0(22.0-32.0)$ & $25.0 \pm 4.0$ & $26.0(14.0-32.0)$ & * \\
\hline \multicolumn{6}{|l|}{ PPD ( $\%$ of sites) } \\
\hline$<3 \mathrm{~mm}$ & $92.8 \pm 5.7$ & $95.0(79.0-99.4)$ & $46.9 \pm 16.1$ & $47.2(17.5-74.0)$ & * \\
\hline $3-5 \mathrm{~mm}$ & $7.2 \pm 5.7$ & $5.1(0.6-21.0)$ & $42.8 \pm 14.6$ & $44.9(19.0-76.3)$ & * \\
\hline$\geq 6 \mathrm{~mm}$ & $0 \pm 0$ & $0(0-0)$ & $9.8 \pm 6.5$ & $9.4(2.3-28.4)$ & * \\
\hline Extent $^{\mathrm{b}}(\%)$ & & $5.23(0.60-20.97)$ & & $52.82(26.0-82.5)$ & + \\
\hline Severity ${ }^{c}(\mathrm{~mm})$ & & $1.00(1.00-1.40)$ & & $2.25(1.39-3.62)$ & + \\
\hline \multicolumn{6}{|l|}{$A L^{d}(\%$ of sites $)$} \\
\hline$<3 \mathrm{~mm}$ & $89.9 \pm 7.0$ & $92.4(72.0-98.6)$ & $35.1 \pm 15.1$ & $37.6(0.6-57.1)$ & * \\
\hline $3-5 \mathrm{~mm}$ & $9.0 \pm 7.0$ & $7.0(1.0-28.0)$ & $46.0 \pm 11.0$ & $46.0(20.0-65.0)$ & * \\
\hline$\geq 6 \mathrm{~mm}$ & $0 \pm 0$ & $0(0-2.0)$ & $17.0 \pm 12.0$ & $13.0(3.0-50.0)$ & * \\
\hline Extent $^{\mathrm{b}}(\%)$ & & $7.63(1.28-28.00)$ & & $62.44(42.86-99.38)$ & + \\
\hline Severity $(\mathrm{mm})$ & & $1.00(1.00-2.27)$ & & $2.58(1.45-4.50)$ & t \\
\hline BOP (\% of sites) & $6.0 \pm 6.0$ & $4.0(0-20.0)$ & $51.0 \pm 30.0$ & $43.0(9.0-100.0)$ & * \\
\hline PI (\% of sites) & $16.0 \pm 7.0$ & $16.0(0-33.0)$ & $68.0 \pm 34.0$ & $64.0(0-100.0)$ & $*$ \\
\hline
\end{tabular}

PPD: probing pocket depth; AL: attachment loss; BOP: bleeding on probing; PI: plaque index; SD: standard deviation; a the greater the PPD, the greater is the risk of periodontitis and inflammation developing, especially if bleeding occurs; ${ }^{b} \%$ affected among all sites; ${ }^{c}$ shows how far beyond 2 mm (normal) was the measured depth or bone loss found in the periodontal diagnosis; ${ }^{\mathrm{d}}$ best indicator of AL of tooth to bone caused by periodontitis. Significant difference between medians of groups by the MannWhitney test: ${ }^{*} p=0.006$ and $+p=0.001$. 
proved kidney disease. However, in this approach it is probable that patients have been included whose kidney disease is unrelated to periodontitis, since in most such patients, the illness stems from primary or hereditary syndromes such as Goodpasture's Syndrome, Bergers Disease, Focal Glomerulosclerosis and Membranoproliferative Glomerulonephritis, or more rarely Alport's Syndrome and Autosomal Dominant Polycystic Kidney Disease, or from secondary processes such as Diabetes Mellitus, Polyarteritis Nodosa, Scleroderma, Myeloma Kidney, Sarcoidosis, Amyloidosis, Lupus Nephritis, etc. ${ }^{35}$ Thus, the constitution of the test group is critical, since the pathological conditions listed above may interfere with some markers, without necessarily being related to periodontitis.

In addition, for a number of years, reference values have been used for various diseases that do not yet signify the actual disease but are close to the upper limit of the normal range. An example is impaired fasting plasma glucose. ${ }^{36}$ The same reasoning could be applied to laboratory assays used as markers for kidney damage, to allow preclinical signs to be detected before the onset of the disease. Thus, by analogy with diabetes, in this study the test and control groups are compared not only with each other but also with kidney dysfunction

Table 2. Serum and urine markers for control subjects and periodontitis patients.

\begin{tabular}{|c|c|c|c|c|c|c|}
\hline Marker & Group & Mean & SD & Median & Minimum & Maximum \\
\hline \multirow{2}{*}{$\begin{array}{l}\text { Serum albumin } \\
(\mathrm{g} / \mathrm{dL})\end{array}$} & Control & 4.9 & 0.5 & 5.0 & 3.4 & 5.8 \\
\hline & Test & 4.7 & 0.4 & 4.7 & 4.1 & 5.6 \\
\hline \multirow{2}{*}{$\begin{array}{l}\text { Serum creatinine } \\
(\mathrm{mg} / \mathrm{dL})\end{array}$} & Control & 0.9 & 0.2 & 0.9 & 0.6 & 1.3 \\
\hline & Test & 1.0 & 0.2 & 1.0 & 0.7 & 1.3 \\
\hline \multirow{2}{*}{$\begin{array}{l}\text { Urine creatinine } \\
\text { (mg/kg.24h) }\end{array}$} & Control & 18.45 & 4.30 & 18.09 & 11.44 & 29.02 \\
\hline & Test & 17.14 & 4.75 & 16.33 & 10.31 & 32.99 \\
\hline \multirow{2}{*}{$\begin{array}{l}\text { Serum uric acid } \\
(\mathrm{mg} / \mathrm{dL})\end{array}$} & Control & 4.3 & 1.7 & 4.1 & 1.3 & 8.0 \\
\hline & Test & 4.9 & 2.1 & 5.0 & 1.4 & 8.9 \\
\hline \multirow{2}{*}{$\begin{array}{l}\text { Urine uric acid } \\
\text { (mg/24h) }\end{array}$} & Control & 542.2 & 219.0 & 520.1 & 194.6 & 1089.0 \\
\hline & Test & 526.5 & 222.1 & 471.1 & 203.5 & 1055.0 \\
\hline \multirow{2}{*}{$\begin{array}{l}\text { Serum urea } \\
(\mathrm{mg} / \mathrm{dL})\end{array}$} & Control & 30 & 9 & 30 & 12 & 48 \\
\hline & Test & 29 & 10 & 28 & 17 & 59 \\
\hline \multirow{2}{*}{$\begin{array}{l}\text { Urine urea } \\
\text { [g/24h] }\end{array}$} & Control & 25.9 & 8.0 & 23.5 & 13.1 & 44.6 \\
\hline & Test & 24.5 & 11.0 & 23.8 & 9.0 & 52.8 \\
\hline \multirow{2}{*}{$\begin{array}{l}\text { Urinary volume } \\
(\mathrm{mL} / 24 \mathrm{~h})\end{array}$} & Control & 1600 & 769 & 1368 & 475 & 3300 \\
\hline & Test & 1402 & 626 & 1405 & 490 & 2700 \\
\hline
\end{tabular}

$\mathrm{SD}$ : standard deviation. Statistical analysis: Student's t-test $(P<.05)$; ${ }^{\text {: }}$ data transformed into logarithms prior to t-test.

Table 3. Glomerular filtration rate estimates in control subjects and periodontitis.

\begin{tabular}{|c|c|c|c|c|c|c|}
\hline Variable used & Group & Mean & SD & Median & Minimum & Maximum \\
\hline \multirow{2}{*}{$\begin{array}{l}\text { Creatinine Clearance } \\
\left(\mathrm{mL} / \mathrm{min} / 1.73 \mathrm{~m}^{2}\right)\end{array}$} & Control & 93.68 & 22.05 & 90.59 & 60.01 & 146.47 \\
\hline & Test & 85.28 & 21.74 & 79.72 & 52.40 & 149.40 \\
\hline \multirow{2}{*}{$\begin{array}{l}{\text { MDRD } 2^{\mathrm{b}}} \\
\left(\mathrm{mL} / \mathrm{min} / 1.73 \mathrm{~m}^{2}\right)\end{array}$} & Control & 81.27 & 13.28 & 77.57 & 62.90 & 115.43 \\
\hline & Test & 78.16 & 12.03 & 76.96 & 62.62 & 127.40 \\
\hline \multirow{2}{*}{$\begin{array}{l}\text { Albumin/Urinary Creatinine } \\
(\mathrm{mg} / \mathrm{g})\end{array}$} & Control & 4.87 & 3.25 & 4.25 & 1.42 & 16.21 \\
\hline & Test & 5.53 & 4.72 & 4.36 & 1.16 & 20.85 \\
\hline
\end{tabular}

MDRD2: the abbreviated Modification of Diet in Renal Disease formula-equation for predictive estimation of glomerular filtration rates. SD: standard deviation. Statistical analysis: ${ }^{a}$ : Student's t-test applied to log-transformed data $(\mathrm{P}<.05)$; ${ }^{\text {b: }}$ : Mann-Whitney test $(\mathrm{P}<.05)$. 
marker reference values. Hence, we would discover whether periodontitis could promote any detectable change in kidney function, even when the marker in question remained within its reference interval, albeit shifted nearer to the upper limit of this range.
Regarding the multivariate canonical correlation analysis, the results for both the control and test groups revealed no more than the other statistical tests, since the correlations found were not relevant. For example, in the control group, the correlation between higher levels of uric acid,

Table 4. Frequency and percentage of control subjects and periodontitis patients whose serum and urine biochemical markers for kidney function are below, within and above their respective reference intervals.

\begin{tabular}{|c|c|c|c|c|c|c|}
\hline \multirow[b]{2}{*}{ Variable } & \multirow[b]{2}{*}{ Classes } & \multicolumn{2}{|c|}{ Control } & \multicolumn{2}{|c|}{ Test } & \multirow[b]{2}{*}{ RI } \\
\hline & & $\mathrm{Fr}$ & $\%$ & $\mathrm{Fr}$ & $\%$ & \\
\hline \multirow{3}{*}{$\begin{array}{l}\text { Serum albumin } \\
(\mathrm{g} / \mathrm{dL})\end{array}$} & within RI & 21 & 70.0 & 25 & 83.3 & $3.5-5.2^{[25]}$ \\
\hline & $<\mathrm{RI}$ & 1 & 3.3 & 0 & 0.0 & \\
\hline & $>\mathrm{RI}$ & 8 & 26.7 & 5 & 16.7 & \\
\hline \multirow{2}{*}{$\begin{array}{l}\text { Serum Creatinine } \\
\text { (mg/dL) }\end{array}$} & within RI & 29 & 96.7 & 29 & 96.7 & $M: 0.9-1.3^{[25]}$ \\
\hline & $<\mathrm{RI}$ & 1 & 3.3 & 1 & 3.3 & W: $0.6-1.1$ \\
\hline \multirow{3}{*}{$\begin{array}{l}\text { Urinary Creatinine } \\
\text { (mg/kg.24hs) }\end{array}$} & within RI & 11 & 36.7 & 9 & 30.0 & $M: 21-26^{[26]}$ \\
\hline & $<\mathrm{RI}$ & 16 & 53.3 & 20 & 66.7 & $W: 16-22$ \\
\hline & $>\mathrm{RI}$ & 3 & 10.0 & 1 & 3.3 & \\
\hline \multirow{3}{*}{$\begin{array}{l}\text { Serum uric acid } \\
\text { (mg/dL) }\end{array}$} & within $\mathrm{RI}$ & 23 & 76.7 & 21 & 70.0 & $M: 3.5-7.2^{[25]}$ \\
\hline & $<\mathrm{RI}$ & 4 & 13.3 & 5 & 16.7 & $W: 2.6-6.0$ \\
\hline & $>\mathrm{RI}$ & 3 & 10.0 & 4 & 13.3 & \\
\hline \multirow{2}{*}{$\begin{array}{l}\text { Urinary uric acid } \\
\text { (mg/24h) }\end{array}$} & within RI & 28 & 93.3 & 29 & 96.7 & $<1000^{[25]}$ \\
\hline & $>\mathrm{RI}$ & 2 & 6.7 & 1 & 3.3 & \\
\hline \multirow{3}{*}{$\begin{array}{l}\text { Serum urea } \\
\text { (mg/dL) }\end{array}$} & within RI & 25 & 83.3 & 25 & 83.3 & $15-40^{[27]}$ \\
\hline & $<\mathrm{RI}$ & 1 & 3.3 & 0 & 0 & \\
\hline & $>\mathrm{RI}$ & 4 & 13.3 & 5 & 16.7 & \\
\hline \multirow{3}{*}{$\begin{array}{l}\text { Urinary urea } \\
\text { (g/24hs) }\end{array}$} & within RI & 12 & 40.0 & 8 & 26.7 & $26-43^{[27]}$ \\
\hline & $<\mathrm{RI}$ & 17 & 56.7 & 18 & 60.0 & \\
\hline & $>\mathrm{RI}$ & 1 & 3.3 & 4 & 13.3 & \\
\hline
\end{tabular}

M: men; W: women; RI: reference interval; Fr: frequency, i.e. number of subjects in each class with respect to RI. Statistical analysis: $c 2$ test $(P<.05)$. Superscripts in square brackets indicate sources.

Table 5. Frequency and percentage of control subjects and periodontitis patients whose glomerular filtration rate variables are below, within and above their reference intervals.

\begin{tabular}{|c|c|c|c|c|c|c|}
\hline \multirow{2}{*}{ Variable } & \multirow{2}{*}{ Classes } & \multicolumn{2}{|c|}{ Control } & \multicolumn{2}{|c|}{ Test } & \multirow{2}{*}{ RI } \\
\hline & & $\mathrm{Fr}$ & $\%$ & $\mathrm{Fr}$ & $\%$ & \\
\hline \multirow{3}{*}{$\begin{array}{l}\text { Creatinine Clearance } \\
\left(\mathrm{mL} / \mathrm{min} / 1.73 \mathrm{~m}^{2}\right)\end{array}$} & within RI & 23 & 76.7 & 20 & 66.7 & $35-44$ years: $74-138^{[25]}$ \\
\hline & $<\mathrm{Rl}$ & 5 & 16.7 & 9 & 30.0 & $45-54$ years: $74-129$ \\
\hline & $>\mathrm{RI}$ & 2 & 6.7 & 1 & 3.3 & $55-64$ years: $69-122$ \\
\hline \multirow{3}{*}{$\begin{array}{l}\text { MDRD2 } \\
\left(\mathrm{mL} / \mathrm{min} / 1.73 \mathrm{~m}^{2}\right)\end{array}$} & within RI & 20 & 66.7 & 20 & 66.7 & $35-44$ years: $74-138^{[25]}$ \\
\hline & $<\mathrm{RI}$ & 10 & 33.3 & 10 & 33.3 & $45-54$ years: $74-129$ \\
\hline & & & & & & $55-64$ years: $69-122$ \\
\hline $\begin{array}{l}\text { Albumin / Urinary } \\
\text { Creatinine (mg/g) }\end{array}$ & within RI & 30 & 100.0 & 30 & 100.0 & $\leq 30^{[28,29]}$ \\
\hline
\end{tabular}

RI: reference interval; Fr: frequency, i.e. number of subjects in each class with respect to RI. MDRD2: the abbreviated Modification of Diet in Renal Disease formula for predictive estimation of glomerular filtration rate. Statistical analysis: $c 2$ test $(\mathrm{P}<.05)$. Superscripts in square brackets indicate sources. 
urinary urea, urine volume and creatinine clearance, and large numbers of teeth and a high proportion of sites with PPD $<3 \mathrm{~mm}$ and between 3 and $5 \mathrm{~mm}$, could be the result of better grinding of food during chewing, leading to enhanced digestion of proteins and nucleoproteins and improved absorption of aminoacids. The same type of explanation could be given for all the apparent correlations in the test group.

Our results are consistent with published data showing that mild, moderate or severe periodontitis was observed in dogs with normal renal function, assessed by serum levels of creatinine and urea and by urine density. ${ }^{37}$ Leivadaros et al ${ }^{38}$ also found no correlation between the urinary albumin/ creatinine ratio and periodontitis, while Taylor et $\mathrm{al}^{39}$ found no change in urea levels after extraction of all teeth from patients suffering from periodontitis.

In another investigation into whether a link exists between periodontitis and renal function, which employed urinary markers of kidney function, such as volume of urine per $24 \mathrm{~h}$ and level of creatinine per 24 hours, and blood markers such as serum creatinine level and creatinine clearance per 24 hours, it was found that the increased incidence of chronic renal failure that occurs with age might enhance the probability of severe periodontitis in the target population. ${ }^{40}$ However, those patients were in a far higher age bracket than the present subjects, averaging 77 years of age. Other authors, who also worked with elderly patients, found an association between periodontitis and kidney disease. ${ }^{41}$ It is known that old age in itself enables the initiation of periodontitis ${ }^{6}$ and thus can be a significant confounding factor in the analysis of the periodontitis - kidney disease relation.

Two methods were used to estimate the glomerular filtration rate, since neither is entirely satisfactory, though creatinine clearance is considered superior. The drawback of creatinine clearance is its dependence on the rigorous collection of all urine for $24 \mathrm{~h}$, while the disadvantage of the predictive abbreviated Modification of Diet in Renal Disease formula is that it is a mathematical model. For independent evidence that the whole urine sample was in fact collected, the albumin/creatinine ratio was measured in a $24 \mathrm{~h}$ urine sample, ${ }^{19}$ even though the original technique for this determination was based on a single ran- dom sample. ${ }^{30}$ Certainly, under these conditions, the ratio between the two concentrations should stay within the reference interval, and this was observed in $100 \%$ of the tests in both groups, indicating that the creatinine clearance results were reliable and thus excluding potentially incomplete urine collection. The values of the glomerular filtration rate, estimated from both creatinine clearance and the abbreviated Modification of Diet in Renal Disease formula, revealed that a high percentage of subjects were within the reference interval in both the control and test groups.

Contradicting our findings, Kshirsagar et $\mathrm{al}^{9}$ reported an association between periodontitis and both raised serum creatinine levels and a glomerular filtration rate below $60 \mathrm{~mL} / \mathrm{min}$ per $1.73 \mathrm{~m}^{2}$, determined by the predictive equation. An association was also observed by Verterinen et al, ${ }^{42}$ however, out of all the clinical variables, radiographic results and analyses of saliva constituents, only the albumin level showed significant change.

Taken together, these data indicate that the study model employed can have a considerable influence on the results. An association between periodontitis and kidney disease is often encountered in studies using a population where kidney disease is already diagnosed. ${ }^{42,43}$ In these cases, the duration of end-stage renal failure and the type of systemic treatment given to patients affect the association significantly. ${ }^{43}$

A similar association has also been observed in a model used to analyze hemodialysis patients. ${ }^{44,45}$ However, even in the study model involving patients with end-stage kidney disease, there is some controversy about the association, since some cases have been reported where periodontal damage was no more severe in such patients. ${ }^{46}$ A recent study suggests that the central process leading to premature death lies primarily in an inability to eliminate bacteria and products from the blood, despite hemodialysis. ${ }^{34}$

Shultis et $\mathrm{al}^{47}$ observed that periodontitis predicts development of overt nephropathy and endstage kidney disease in individuals with type 2 diabetes. In groups as complex as hemodialysis patients and diabetics, such associations become hard to analyze or discuss.

It is our view that the model used in the present study to assess whether periodontitis is correlated with kidney disease suffers from fewer confound- 
ing factors (tobacco, pregnancy, hormonal contraceptives, antibiotics and inflammatory treatment, cardiac and renal problems) than many models found in the literature and it is more reliable than one involving diabetic patients, since the sequelae of diabetes are very complex and generate several kinds of interference, apart from the known tendency of diabetes per se to promote infectious processes. ${ }^{48}$

One limitation of this study is its cross-sectional design. Longitudinal studies are still necessary, either to consolidate the above negative results or perhaps to show that chronic periodontitis is, after all, a risk factor for kidney disease, by detecting subtle changes, within the reference intervals, following treatment for periodontitis.

Another limitation of the present study is that, despite the clearcut statistical difference between the control and test groups, $10 \%$ of sites $\geq 6 \mathrm{~mm}$ might not have the severity of periodontitis necessary to trigger systemic reactions. In other words, it is unknown how many deep pockets with bleeding on probing and for how long these pockets have to be there before we can measure a systemic reaction. Furthermore, there might be specific bacterial species that trigger stronger systemic responses than others. Such problems make it very difficult to evaluate the real effect of periodontitis on systemic health.

Therefore, the absence of correlation observed between periodontitis and kidney disease in healthy adults leaves room for the possibility that severely impaired kidneys prepare the field for the progression of periodontitis or vice versa. ${ }^{34}$

\section{CONCLUSIONS}

Within the limitations of this study and the methodology utilized, it may be suggested from the results that severe periodontitis was not correlated with renal dysfunction in the studied population. Further studies on therapeutic intervention (tests before and after treatment) would make an important contribution to the consolidation of these results.

\section{ACKNOWLEDGMENTS}

We thank: MA Dangona, TN Nunes and FES Pavarina for technical assistance, Prof. Dr. José Silvio Govone for help with the statistical analysis and the Foundation for the Development of the
University of the State of São Paulo (FUNDUNESP) and the Scientific Research Aid Program of the Araraquara School of Pharmaceutical Sciences, UNESP (PADC-FCF-Araraquara-UNESP) for financial support.

\section{REFERENCES}

1. American Academy of Periodontology. International workshop for a classification of periodontal disease and conditions. Ann Periodontol 1999;4:1-112.

2. Armitage GC. Classifying periodontal disease - a longstanding dilemma. Periodontol 2000 2002;30:9-32.

3. Nishihara T, Koseki T. Microbial etiology of periodontitis. Periodontol 2000 2004;36:14-36.

4. Kinane D, Bouchard P. Periodontal diseases and health: consensus report of the sixth European workshop on periodontology. J Clin Periodontol 2008;35(suppl.8):333-337.

5. Jansson L, Lavstedt S, Frithiof I, Theobald H. Relationship between oral health and mortality in cardiovascular diseases. J Clin Periodontol 2001;28:762-768.

6. Josiphura K, Ritchie CS. Strength of evidence relating periodontal disease and cardiovascular disease. Inside Dent 2006;2:1-9.

7. Sim SJ, Kim HD, Moon JY, Zavras Al, Zdanowicz J, Jang SJ, Jin $\mathrm{BH}$, Bae KH, Paik DI, Gouglass CW. Periodontitis and the risk for non-fatal stroke in Korean adults. J Periodontol 2008;79:1652-1658.

8. Tuominen R, Reunanen A, Paunio M, Paunio J, Aromaa A. Oral health indicators poorly predict coronary heart disease deaths. J Dent Res 2003;82:713-718.

9. Kshirsagar AV, Moss KL, Elter JR, Beck JD, Offenbacher S, Falk RJ. Periodontal disease is associated with renal insufficiency in the atherosclerosis risk in communities (ARIC) study. Am J Kidney Dis 2005;45:650-657.

10. Scannapleco FA, Panesar M. Periodontitis and chronic kidney disease. J Periodontol 2008;79:1617-1619.

11. Fisher MA, Taylor GW. A prediction model for chronic kidney disease includes periodontal disease. J Periodontol 2009;80:16-23.

12. DeBowes LJ, Mosier D, Logan E, Harvey CE, Lowry S, Richardson DC. Association of periodontal disease and histopathologic lesions in multiple organs from 45 dogs. $J$ Vet Den 1996;13:57-60.

13. Yamalik N, Delilbasi L, Gulay H, Caglayan F, Haberal M, Caglayan $\mathrm{G}$. The histological investigation of gingiva from patients with chronic renal failure, renal transplants, and periodontitis: a light and electron microscopic study. $J$ Periodontol 1991;62:737-744. 
14. Rahman MM, Caglayan F, Rahman B. Periodontal health parameters in patients with chronic renal failure and renal transplants receiving immunosuppressive therapy. J Nihon Univ Sch Dent 1992;34:265-272.

15. Fisher MA, Taylor GW, Shelton BJ, Jamerson KA, Rahman $M$, Ojo AO, Sahgal AR. Periodontal disease and other nontraditional risk factors for CKD. Am J Kidney Dis 2008;51:4552.

16. Delaney MP, Price CP, Newman DJ, Lamb E. Kidney disease. In: Burtis CA, Ashwood ER, Bruns DE, eds. Tietz textbook of clinical chemistry and molecular diagnosis. 4th ed. St Louis: Elsevier Saunders, 2006:1671-1746.

17. Nogueira DM, Strufaldi B, Hirata MH, Abdalla DSP, Hirata RDC. Exploração funcional do rim. In: Nogueria DM, eds. Métodos de bioquímica clínica: técnica e interpretação. São Paulo: Pancast, 1990:139-151.

18. National Kidney Foundation. K/DOQI clinical practice guidelines for chronic kidney disease: evaluation, classification, and stratification. Part 2. Am J Kidney Dis 2002;39:S79-S92.

19. Alves MAR. Diagnóstico de doença renal crônica: avaliação de proteinúria e sedimento urinário. J Bras Nefrol 2004;26:6-7.

20. Machtei EE, Christersson LA, Grossi SG, Dunford R, Zambon JJ, Genco RJ. Clinical criteria for the definition of "Established Periodontitis". J Periodontol 1992;63:207-215.

21. Beck JD, Offenbacher S. Relationships among clinical measures of periodontal disease and their associations with systemic markers. Ann Periodontol 2002;7:70-89.

22. Pearson TA, Mensah GA, Alexander RW, Anderson JL, Cannon RO, Criqui M, Fadl YY, Fortmann SP, Hong Y, Myers GL, Rifai N, Smith Jr SC, Taubert K, Tracy RP, Vinicor F. Markers of inflammation and cardiovascular disease: application to clinical and public health practice: a statement for healthcare professionals from the Centers for Disease Control and Prevention and the American Heart Association. Circulation 2003;107:499-511.

23. Haffajee AD, Bogren A, Hasturk H, Feres M, Lopez NJ, Socransky SS. Subgingival microbiota of chronic periodontitis subjects from different geographic locations. J Clin Periodontol 2004;31:996-1002.

24. Carlos JP, Wolfe MD, Kingman A. The extent and severity index: a simple method for use in epidemiologic studies of periodontal disease. J Clin Periodontol 1986;13:500-505.

25. Lamb E, Newman DJ, Price CP. Kidney Function Tests. In: Burtis CA, Ashwood ER, Bruns DE, eds. Tietz textbook of clinical chemistry and molecular diagnostics. 4th ed. St. Louis: Elsevier Saunders, 2006:797-835.
26. Johnson AM. Amino acids, peptides, and proteins. In: Burtis CA, Ashwood ER, Bruns DE, eds. Tietz textbook of clinical chemistry and molecular diagnostics. 4th ed. St. Louis: Elsevier Saunders, 2006:533-595.

27. Roberts LW, MC Millin GA, Burtis CA, Bruns DE. Reference information for the clinical laboratory. In: Burtis CA, Ashwood ER, Bruns DE, eds. Tietz textbook of clinical chemistry and molecular diagnostics. 4th ed. St. Louis: Elsevier Saunders, 2006:2251-2318.

28. Owen JA, Iggo B, Scandrett FF, Steward CP. The determination of creatinine in plasma serum, and in urine; a critical examination. Biochem J 1954;58:426-437.

29. Shephard MD, Penberthy LA, Fraser CG. Short- and longterm biological variation in analytes in urine of apparently healthy individuals. Clin Chem 1981;27:569-573.

30. Johnson CA, Levey AS, Coresh J, Levin A, Lau J, Eknoyan G. Clinical practice guidelines for chronic kidney disease in adults: Part I. Definition, disease stages, evaluation, treatment, and risk factors. Am Fam Physician 2004a;70:869-876.

31. Johnson CA, Levey AS, Coresh J, Levin A, Lau J, Eknoyan G. Clinical practice guidelines for chronic kidney disease in adults: Part II. Glomerular filtration rate, proteinuria, and other markers. Am Fam Physician 2004b;70:1091-1097.

32. Brotto RS Evaluation of the cardiovascular risk on subjects with periodontitis [Masters Dissertation] [Internet]. Araraquara: Faculty of Pharmaceutical Sciences, UNESP; 2007 Available at <http://dominiopublico.gov.br,>. Accessed August 25, 2009.

33. Socransky SS, Haffajee AD, Cugini, MA, Smith C, Kent Jr RL. Microbial complexes in subgingival plaque. J Clin Periodontol 1998;25:134-144.

34. Sendy J, Horta E, Foltán R, Spackova J, Dusková J. Mechanism of increased mortality in hemodialysed patients with periodontitis. Med Hypotheses 2009; about 3 p.

35. Black RM. Rose \& Black's Clinical problems in nephrology. Boston: Little, Brown and Company, 1996.

36. Sacks DB. Carbohydrates In: Burtis CA, Ashwood ER, Bruns $D E$, eds. Tietz textbook of clinical chemistry and molecular diagnostics. 4th ed. St Louis: Elsevier Saunders, 2006. p.837901.

37. Barbudo-Selmi GR, Carvalho MB, Selmi AL, Selmi AL, Martins SEC. Periodontal disease characterization in dogs with normal renal function or chronic renal failure. Ciênc Rural 2004;34:113-118.

38. Leivadaros E, Van der Velden U, Bizarro S, Tem Heggeler JMAG, Gerdes VEA, Hoek FJ, Nagy TOM, Scholma J, Bakker SJL, Gans ROB, Tem CH, Loos BG. A pilot study into measurements of markers of atherosclerosis in periodontitis. $J$ Periodontol 2005;76:121-128. 
39. Taylor BA, Tofler GH, Carey HMR, Morel-Kopp MC, Philcox S, Carter TR, Elliot MJ, Kull AD, Ward C, Schenck K. Full-mouth tooth extraction lowers systemic inflammatory and thrombotic markers of cardiovascular risk. J Dent Res 2006;85:74-78.

40. Yoshihara A, Deguchi T, Hanada N, Miyazaki H. Renal function and periodontal disease in elderly Japanese. $J$ Periodontol 2007;78:1241-1248.

41. Kshirsagar AV, Offenbacher S, Moss KL, Barros SP, Beck JD. Antibodies to periodontal organisms are associated with decreased kidney function. The dental atherosclerosis risk in communities study. Blood Purif 2007;25:125-132.

42. Vesterinen M, Ruokonen H, Leivo T, Honkanen AM, Honkanen E, Karj K, Lindqvist C, Meurman JH. Oral health and dental treatment of patients with renal disease. Quintessence Int 2007;38:211-219.

43. Davidovich E, Schwarz Z, Davidovitch M, Eidelman E, Bimstein E. Oral findings and periodontal status in children, adolescents and young adults suffering from renal failure. J Clin Periodontol 2005;32:1076-1082.

44. Bayraktar G, Kurtulus T, Duraduryan A, Cintan S, Kazancioglu, Yildiz A, Bural C, Bozfakioglu S, Besler M, Trablus S, Issever $\mathrm{H}$. Dental and periodontal findings in hemodialysis patients. Oral Dis 2007;13:393-397.

45. Borawski J, Wilczynska-Borawska M, Stokowska W, Mysliwiec M. The periodontal status of pre-dialysis chronic kidney disease and maintenance dialysis patients. Nephrol Dial Transplant 2007;22:457-464.

46. Castillo A, Mesa F, Liébana J, Garcia-Martinez O, Ruiz S, Garcia-Valdecasas J, O'Valle F. Periodontal and oral microbiological status of an adult population undergoing haemodialysis: a cross-sectional study. Oral Dis 2007;13:198205.

47. Shultis WA, Weil EJ, Looker HC, Curtis JM, Shlossman M, Genco RJ, Knowler WC, Nelson RG. Effect of periodontitis on overt nephropathy and end-stage renal disease in type 2 diabetes. Diabetes Care 2007;30:306-311.

48. Felig $P$, Bergman M. The endocrine pancreas: Diabetes mellitus. In: Felig P, Baxter JD, Frohman LA, eds. Endocrinology and Metabolism. 3rd ed. New York: McGraw-Hill Inc, 1995:1107-1250. 